\title{
Relationship between body mass index, age and upper airway measurements in snorers and sleep apnoea patients
}

\author{
P. Mayer*†, J-L. Pépin*, G. Bettega**, D. Veale*+, \\ G. Ferretti++, C. Deschaux*, P. Lévy**
}

Relationship between body mass index, age and upper airway measurements in snorers and sleep apnoea patients. P. Mayer, J-L. Pépin, G. Bettega, D. Veale, G. Ferretti, C. Deschaux, P. Lévy. CERS Journals Ltd 1996.

ABSTRACT: Anatomical pharyngeal and craniofacial abnormalities have been reported using upper airway imaging in snorers with or without obstructive sleep apnoea (OSA). However, the influences of the age and weight of the patient on these abnormalities remain to be established. The aim of this study was, therefore, to evaluate in a large population of snorers with or without OSA, the relationship between body mass index (BMI), age and upper airway morphology.

One hundred and forty patients were referred for assessment of a possible sleeprelated breathing disorder and had complete polysomnography, cephalometry and upper airway computed tomography.

For the whole population, OSA patients had more upper airway abnormalities than snorers. When subdivided for BMI and age, however, only lean or younger OSA patients were significantly different from snorers as regards their upper airway anatomy. The shape of the oropharynx and hypopharynx changed significantly with BMI both in OSA patients and snorers, being more spherical in the highest BMI group due mainly to a decrease in the transverse axis. On the other hand, older patients ( $>63 \mathrm{yrs}$ ), whether snorers or apnoeics, had larger upper airways at all pharyngeal levels than the youngest group of patients $(<52 \mathrm{yrs})$. For the total group of patients, upper airway variables explained $26 \%$ of the variance in apnoea/hypopnoea index $(\mathrm{AHI})$, whereas in lean $\left(\mathrm{BMI}<27 \mathrm{~kg} \cdot \mathrm{m}^{-2}\right.$ ) or youngest (age $<52 \mathrm{yrs}$ ) subjects upper airway variables explained, respectively 69 and $55 \%$ of the variance in AHI.

In conclusion, in lean or young subjects, upper airway abnormalities explain a major part of the variance in apnoea/hypopnoea index and are likely to play an important physiopathogenic role. This study also suggests that the shape of the pharyngeal lumen in awake subjects is more dependent on body mass index than on the presence of obstructive sleep apnoea. Further investigation looking at upper airway imaging for surgical selection in obstructive sleep apnoea should focus on lean and young patients.

Eur Respir J., 1996, 9, 1801-1809.

\begin{abstract}
*Dept of Respiratory Medicine and Sleep Laboratory, ${ }^{+}$ANTADIR, **Dept of Maxillofacial Surgery, ${ }^{++}$Dept of Radiology, $\stackrel{\ddagger}{+}$ RETA Laboratory, University Hospital, Grenoble, France. 'Dept of Respiratory Medicine, Hôtel-Dieu de Montréal, Montreal University, Quebec, Canada.
\end{abstract}

Correspondence: P. Lévy

Département de Pneumologie

Unité Sommeil et Respiration

CHU de Grenoble

BP $217 \mathrm{X}$

38043 Grenoble

France

Keywords: Age

body mass index

obstructive sleep apnoea

pathophysiology

snoring

upper airway imaging

Received: November 241995

Accepted after revision May 21996
Upper airway and craniofacial anatomical abnormalities have been described in snorers [1-3] and obstructive sleep apnoea (OSA) patients [1-27]. When compared to snorers, OSA patients have been found to have increased soft palate length and the hyoid bone displaced inferiorly $[1,2]$. In OSA, cessation of breathing occurs because of repetitive occlusion of the upper airway, but upper airway abnormalities are generally weakly correlated with apnoea severity, expressed either as apnoea/hypopnoea index (AHI) or desaturation index, and explain only a low percentage of the variance in AHI $[1,4]$. This reflects the complexity of the pathophysiology of OSA and questions the pathophysiological relationship between obstructive sleep apnoea and upper airway abnormalities.

There is evidence that OSA patients with a low body mass index (BMI) may have a higher incidence of upper airway abnormalities [4]. Also, in OSA patients, upper airway morphology seems to differ according to neck size or BMI. Obese patients show increased upper airway soft tissue dimensions, and non-obese patients demonstrate abnormal craniofacial structure, while intermediate patients have both craniofacial and upper airway softtissue abnormalities [26]. In addition, it has been suggested that upper airway morphology changes with age, as shown by an increase in the distance from the mandibular plane to the hyoid bone (MP-H) [2] in older controls, while the pharyngeal cross-sectional area has been described either as reduced [12, 20] or enlarged [22, 25] in elderly subjects. These conflicting results suggest that in apnoeics of different age [25] or weight, different anatomical or physiological mechanisms may play the major role in the propensity to apnoea.

The aim of this study was, therefore, to evaluate, in a large population of snorers with or without OSA, the relationships between BMI, age and upper airway morphology. Upper airway imaging was performed by cephalometry 
and computed tomography (CT) which are complementary techniques in terms of skeletal and soft tissue evaluation. We hypothesized that both the type of upper airway abnormalities and their importance in OSA pathophysiology will be different according to the BMI or the age of the patients.

\section{Methods}

\section{Patients}

One hundred and forty consecutive patients referred to a regional University Sleep Laboratory for a suspected sleep-related breathing disorder (SRBD) were included in the study. Disease was suspected on the basis of a history of snoring, with or without daytime hypersomnolence or chronic fatigue.

\section{Study design}

A retrospective analysis of a cohort of patients who underwent complete polysomnography, lateral cephalometry and computed tomography of the pharynx at their initial evaluation was performed. Patients were stratified according to: their AHI ( $<15$ or $\geq 15$ disordered breathing events $\left.\cdot h^{-1}\right)$; their age $(<52,52-63,>63 \mathrm{yrs})$; or their BMI $\left(<27,27-30,>30, \mathrm{~kg} \cdot \mathrm{m}^{-2}\right)$. To investigate the effect of age and BMI on upper airway morphology and implications for OSA pathophysiology, upper airway measurements were compared in the different age and BMI subgroups, and also between patients with an AHI $<15$ $v s \geq 15$. Correlation between upper airway measurements and AHI and multiple stepwise regression analysis with $\mathrm{AHI}$ as the dependent variable were also performed for the overall population and the different age and BMI subgroups.

\section{Upper airway imaging}

Cephalometry. Lateral cephalometric radiographs were obtained using the technique described by RILEY et al. [5]. Briefly, the patient was seated with his head in a neutral position, with the gaze parallel to the floor and the teeth together. The radiographic plate was placed next to the left side of the face and the cone $1.5 \mathrm{~m}$ from the patient. Exposures were taken while the patient slowly exhaled a moderately deep breath. The following measurements were made from the radiograph: 1) MP-H distance (position of the hyoid bone), from the mandibular plane (a plane constructed from gnathion $(\mathrm{Gn})$ through gonion (Go)) to the hyoid bone $(\mathrm{H}) ; 2$ ) the posterior airway space (PAS), measured between the posterior pharyngeal wall and the dorsum of the tongue on a line joining gonion (Go) to the supamentale (A); 3) PNS-P (length of the soft palate), from the posterior nasal spine to the tip of the palate; 4) soft palate width (SPW), maximal width of soft palate measured on cephalometry; and 5) mandibular length and position (as described by RIVLIN et al. [9]) (fig. 1a).

The following definitions were used for this evaluation: a) "supramentale", the point of greatest concavity on the anterior surface of the symphysis of the mandible; b) "condylion", the most superior and posterior point on the head of the mandibular condyle; c) "sella", the centre of the hypophyseal fossa (sella turcica); "horizontal reference plane" (HRP) (mean occlusal plane), a horizontal axis or reference line; this plane passes interocclusally between the maxillary and mandibular first permanent molars and bisects the incisor overlap; "mandibular length", the distance from A to B in mm, as projected on the HRP; "mandibular position", the distance from B to $\mathrm{C}$ in $\mathrm{mm}$, as projected on the HRP (this distance depends on three factors: vertical orientation of the mandible; angle of HRP and position of the condylion (point $\mathrm{B}$ ) relative to the cranial base (c), a vertical and posterior displacement of the mandible resulting in a greater HRP angle and a shorter B-C length [27]); "posterior mandibular displacement", the distance from $\mathrm{A}$ to $\mathrm{C}$ in $\mathrm{mm}$ as projected on the HRP.

Computed tomography $(C T)$. CT scanning was used to measure the minimal luminal area of the airway at the level of the nasopharynx (NP) (upper limit (UL): cranial base; lower limit (LL): posterior border of the hard palate), oropharynx (OP) (UL: posterior border of the hard palate; LL: tip of the soft palate), and hypopharynx (HP) (UL: tip of the soft palate; LL: tip of the epiglottis). Scans were performed on a CE 12,000 CGR computed tomographic scanner, with a $3.4 \mathrm{~s}$ scan time. Patients were observed closely to ensure that they remained awake throughout the procedure and did not swallow during imaging. Scanning was performed during quiet breathing. The subjects were placed in the supine position on the scanning table, with the neck placed in a neutral position midway between flexion and extension. Two sections were obtained from the level of the nares and the maxillary sinus in order to detect any nasal occlusion or other anatomical abnormality at these levels. Five millimetre thick slices were made every $10 \mathrm{~mm}$ from the hard palate to the epiglottis. Care was taken to ensure that all cuts were perpendicular to the airway lumen to allow accurate assessment of the cross-sectional area. For this purpose, an integral software programme was used to determine the contours of the pharyngeal lumen.

To appreciate the shape of the pharyngeal lumen the anteroposterior (AP) and transverse (T) diameters were also measured at all pharyngeal levels and expressed as a ratio $(\mathrm{AP} / \mathrm{T})$. The size of the base of tongue was estimated (as described by LARSSON et al. [15]) (fig. 1c) by the measurement of the interhyoglossal distance (IHL) and the genioglossal width $(\mathrm{GW})$ at the intersection with the hyoglossus. Finally, the skeletal boundary enclosing the upper airway was evaluated as described by SHELTON et al. [23]. For this purpose, the area between the mandibular rami at a level just below the hard palate (Surface $(\mathrm{Su})$ ) was determined (using a formula for a trapezoid) and the distance between the incisors and the middle of the line joining the posterior borders of the mandibular rami (Distance (L)) was measured (fig. 1b) The window settings were standardized for all of the patients.

\section{Sleep studies}

Overnight polysomnography was performed in a standard fashion [28], and was scored manually according to RECHTSCHAFFEN and KALES criteria [29]. Episodes of apnoea were defined as complete cessation of airflow for 
a)

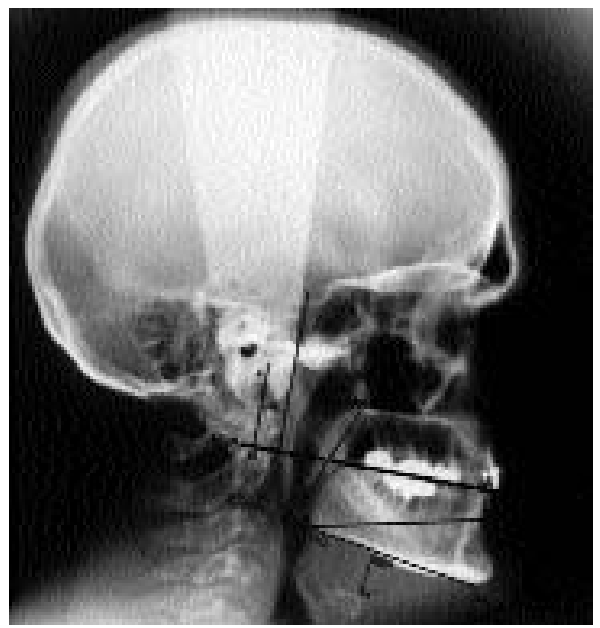

b)

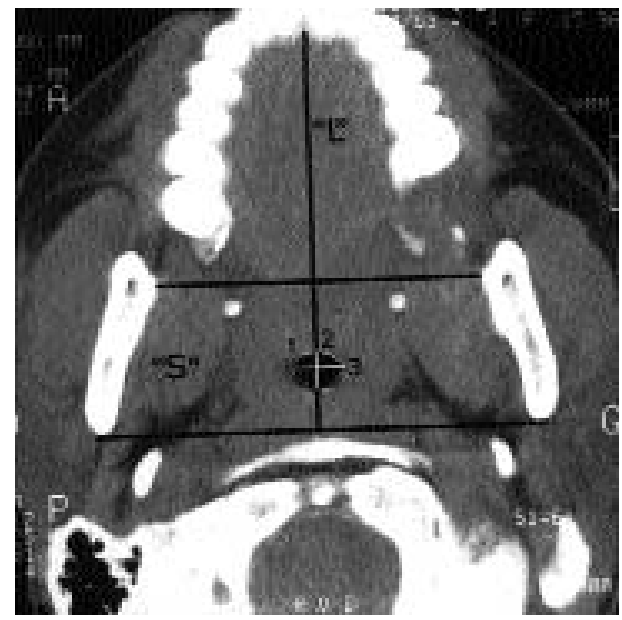

c)

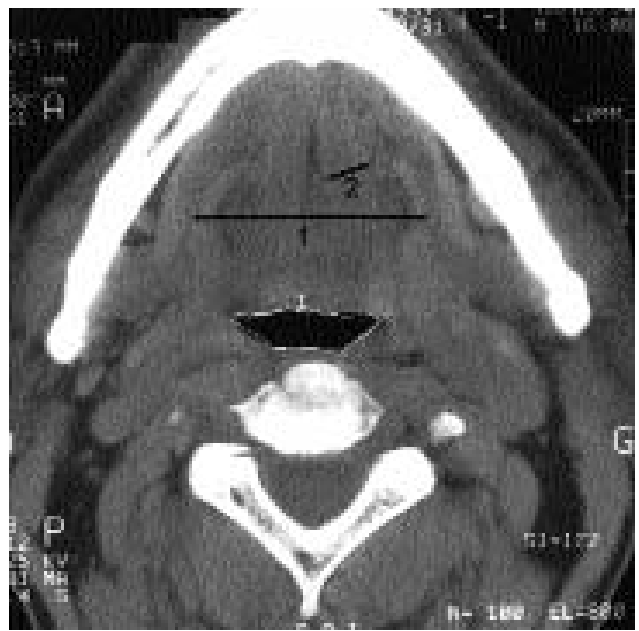

Fig. 1. - Representation of the different parameters measured on cephalometry and computed tomography. a) Cephalometry; measurements of soft palate length (PNS-P), pharyngeal posterior airway space (PAS), distance from mandibular plane to hyoid bone (MP-H), length (A-B), position relative to the cranial base (B-C) and posterior displacement (A-C) of the mandible, as projected on the horizontal reference plane (HRP). b) Computed tomography: measurement of oropharyngeal area (1), antero-posterior diameter (2), transverse diameter (3), surface "Su" (area between the mandibular rami at a level just under the hard palate), and distance "L" (length between the incisors and the middle of the line joining the posterior borders of the mandibular rami) and representing the skeletal boundary enclosing the upper airway. c) Tongue evaluation (CT): measure of interhyoglossal length (IHL) (1) and genioglossal width (GW) (2).
$10 \mathrm{~s}$ or more, and hypopnoea as a greater than $50 \%$ decrease in oronasal airflow lasting for at least $10 \mathrm{~s}$. Apnoea/hypopnoea events were classified as obstructive, mixed or central according to the presence or the absence of breathing efforts and the AHI (number of episodes of apnoea + hypopnoea per hour of sleep) [30] was calculated. OSA was defined as an AHI $\geq 15$. Patients with an AHI $<15$ were considered as nonapnoeic or mild-apnoeic snorers.

\section{Statistical analysis [31]}

To test whether there was a relationship between BMI, age and upper airway measurements, and also to evaluate the importance of upper airway measurements in the pathogenesis of OSA, the following techniques were employed.

Firstly, the population was stratified by BMI using cutoff points of $<27$ (lean), 27-30, $>30$ (obese) $\mathrm{kg} \cdot \mathrm{m}^{-2}$ or age using cut off points of $<52$ (younger), 52-63, $>63$ (old) yrs. Age cut-off points were chosen in order to have equal-sized groups. An analysis of variance (ANOVA) was performed to evaluate the differences between the mean values of upper airway measurements in the different BMI and age subgroups. Subsequently, the population was subdivided for AHI, $<15$ (snorers), $\geq 15$ (OSA patients) events $\cdot h^{-1}$ and two-way ANOVA for BMI and $\mathrm{AHI}$, and age and AHI were performed for each upper airway variable. Equality of group variability was always tested by a Levene analysis. When the variance was not equal in each group for each factor, a BrownForsythe analysis was performed in place of the classic Pooled-Variance test. When the ANOVA was significant, a Bonferroni test was then used for multiple comparisons. Upper airway measurements of OSA patients and snorers were compared in the overall population (not subdivided for BMI or age) and in the different groups of BMI and age using Student's t-test or chi-squared, when the distribution was normal, or a Mann-Whitney test. A p-value of less than 0.05 was judged to be statistically significant.

Secondly, to evaluate the importance of upper airway measurements in OSA pathogenesis, Pearson correlation coefficient analysis was performed between all variables, including anthropometric data and upper airway measurements, and $\mathrm{AHI}$ in the overall population and in the different groups of BMI and age. A multiple, stepwise, linear regression analysis was also performed to identify which variables best explained the variance in AHI. Independent variables (MP-H, PNS-P, PAS, NP area, OP area, HP area, IHL, GW, Su, L, A-B, B-C, A$\mathrm{C}$, age and $\mathrm{BMI}$ ) were integrated into the model. The dependant variable was the AHI. Only the variables with an F-value $>4$ were finally kept in the formula. Results are expressed as the percentage of the variance of the AHI explained by the formula. This analysis was performed for the overall population and for each predefined subgroup of BMI and age.

\section{Results}

Anthropometric and sleep characteristics of the population are summarized in tables 1 and 2 for BMI and 
Age subgroups. Overall, the OSA patients were more obese and older than snorers.

\section{Upper airway measurements in OSA patients and snorers}

Overall population. Comparing OSA patients to snorers (table 3), on cephalometry, OSA patients had a longer soft palate (PNS-P), a hyoid bone displaced inferiorly (increased $\mathrm{MP}-\mathrm{H}$ ), and a posteriorly displaced mandible (shorter B-C length). In OSA patients, this was associated on $\mathrm{CT}$ with an increased size of the base of tongue as evaluated by the interhyoglossal length (IHL) and the genioglossal width $(\mathrm{GW})$. Also, there was a decrease in the transverse width of the oropharynx (OP) in OSA patients, which results in an augmentation of the AP/T ratio. However, the transverse axis was the dominant axis at all levels of the pharynx, with the $\mathrm{AP} / \mathrm{T}$ ratio always $<1$. Comparison of other variables revealed no differences between groups.

Subgroups of BMI and age. Most of the differences found in the overall population were retrieved in lean (BMI $<27 \mathrm{~kg} \cdot \mathrm{m}^{-2}$ ) or younger (age $<52 \mathrm{yrs}$ ) groups (fig. 2). In effect, lean or younger OSA patients compared to lean

Table 1. - Anthropometric and sleep characteristics of OSA patients and snorers

\begin{tabular}{lccc}
\hline & $\begin{array}{c}\text { OSA } \\
\mathrm{n}=94\end{array}$ & $\begin{array}{c}\text { Snorers } \\
\mathrm{n}=46\end{array}$ & p-value \\
\hline Sex M/F & $81 / 13$ & $40 / 6$ & $\mathrm{NS}$ \\
Age yrs & $58 \pm 12$ & $53 \pm 12$ & $<0.05$ \\
BMI kg·m ${ }^{-2}$ & $33 \pm 8$ & $30 \pm 6$ & $<0.01$ \\
AHI events $\mathrm{h}^{-1}$ & $47 \pm 22$ & $7 \pm 4$ & $<0.01$ \\
TST min & $444 \pm 105$ & $425 \pm 89$ & $\mathrm{NS}$ \\
SE \% & $83 \pm 13$ & $81 \pm 11$ & $\mathrm{NS}$ \\
Stage 1-2 sleep $\dagger$ & $90 \pm 8$ & $85 \pm 10$ & $<0.01$ \\
Stage 3-4 sleep $\dagger$ & $1 \pm 4$ & $4 \pm 6$ & $<0.01$ \\
REM sleep $\dagger$ & $8 \pm 6$ & $10 \pm 6$ & 0.05 \\
Mean $\mathrm{Sa}_{\mathrm{a}} \mathrm{O}_{2} \%$ & $89 \pm 5$ & $93 \pm 1.9$ & $<0.01$ \\
Minimal $\mathrm{Sa}_{\mathrm{a}} \mathrm{O}_{2} \%$ & $66 \pm 18$ & $80 \pm 10$ & $<0.01$ \\
\hline
\end{tabular}

Values are presented as mean \pm SD. \#: OSA versus snorers. OSA: obstructive sleep apnoea; M: male; F: female; BMI: body mass index; AHI: apnoea/hypopnoea index; TST: total sleep time; SE: sleep efficiency (TST/time in bed); ${ }^{\dagger}$ \% TST; REM: rapid eye movement; $\mathrm{Sa}_{\mathrm{a}} \mathrm{O}_{2}$ : arterial oxygen saturation; NS: nonsignificant. or younger snorers had increased PNS-P, a hyoid bone displaced inferiorly, and a posteriorly displaced mandible. The hypopharynx was significantly smaller only in younger snorers compared to younger OSA patients. Other upper airway measurements were not significantly different between lean or younger OSA patients and snorers. In the BMI class $27-30 \mathrm{~kg} \cdot \mathrm{m}^{-2}$, the only significant differences found between OSA patients and snorers were in the size of the tongue base, IHL and GW, which were larger in OSA patients $(50.6 \pm 4$.1 vs $45 \pm 8.3$ and $11 \pm 1.9$ vs $9 \pm 1.2 \mathrm{~mm}$, respectively), while in the age class 52-63 yrs only GW was significantly larger in OSA patients $v s$ snorers $(11.1 \pm 2.3$ vs $9.4 \pm 1.6 \mathrm{~mm})$. No significant differences were found between OSA patients and snorers in the BMI class $>30 \mathrm{~kg} \cdot \mathrm{m}^{-2}$ or age $>63 \mathrm{yrs}$.

Table 3. - Cephalometric and computed tomography measurements of OSA patients and snorers

\begin{tabular}{lccc}
\hline & $\begin{array}{c}\text { OSA } \\
\mathrm{n}=94\end{array}$ & $\begin{array}{c}\text { Snorers } \\
\mathrm{n}=46\end{array}$ & p-value $^{\#}$ \\
\hline Cephalometry & $\mathbf{}$ & \\
PNS-P & & & \\
MP-H & $44.7 \pm 5.2$ & $42.1 \pm 5.3$ & $<0.01$ \\
PAS & $20.5 \pm 6.8$ & $16.8 \pm 6.8$ & $<0.01$ \\
SPW & $13.4 \pm 4.7$ & $12.5 \pm 3.8$ & NS \\
A-B length & $12.1 \pm 2.5$ & $11.6 \pm 2.8$ & NS \\
B-C length & $87.5 \pm 7.5$ & $87.8 \pm 6.4$ & NS \\
A-C length & $11.7 \pm 4.2$ & $13.3 \pm 3.4$ & 0.02 \\
Computed tomography & $75.8 \pm 8.2$ & $74.4 \pm 6.9$ & NS \\
NP area mm 2 & $375 \pm 128$ & $387 \pm 110$ & NS \\
OP area mm & $85 \pm 57$ & $95 \pm 55$ & NS \\
HP area mm 2 & $245 \pm 142$ & $207 \pm 136$ & NS \\
Su cm & $22.2 \pm 3.4$ & $21.7 \pm 3.4$ & NS \\
L cm & $71.3 \pm 5.9$ & $71.1 \pm 5.9$ & NS \\
AP/T ratio NP & $0.81 \pm 0.23$ & $0.86 \pm 0.26$ & NS \\
AP/T ratio OP & $0.63 \pm 0.39$ & $0.49 \pm 0.27$ & 0.02 \\
AP/T ratio HP & $0.83 \pm 0.41$ & $0.71 \pm 0.37$ & NS \\
IHL mm & $51.2 \pm 6.1$ & $48.0 \pm 5.6$ & $<0.01$ \\
GW mm & $10.8 \pm 2.0$ & $9.8 \pm 1.4$ & $<0.01$ \\
\hline
\end{tabular}

Values are presented as mean \pm SD. \#: OSA versus snorers. PNSP: soft palate length; MP-H: distance from mandibular plane to hyoid bone; PAS: pharyngeal posterior airway space; A-B, $\mathrm{B}-\mathrm{C}$ and A-C length: mandibular length, position and posterior displacement, respectively; NP, OP and HP: naso-, oro- and hypopharynx area; Su: surface; L: distance; AP/T: anteroposterior/transverse axis ratio; IHL: interhyoglossal length; GW: genioglossal width; OSA obstructive sleep apnoea; NS: nonsignificant.

Table 2. - Characteristics of subgroups of BMI and age

\begin{tabular}{|c|c|c|c|c|c|c|c|c|c|}
\hline \multirow[b]{2}{*}{ Population } & \multicolumn{3}{|c|}{$<27$} & \multicolumn{3}{|c|}{$\begin{array}{c}\text { BMI } \mathrm{kg} \cdot \mathrm{m}^{-2} \\
27-30\end{array}$} & \multicolumn{3}{|c|}{$>30$} \\
\hline & All & OSA & Snorers & All & OSA & Snorers & $\overline{A l l}$ & OSA & Snorers \\
\hline Subject $n$ & 36 & 17 & 19 & 32 & 21 & 11 & 72 & 56 & 16 \\
\hline Age yrs & $52 \pm 14$ & $57 \pm 15^{*}$ & $48 \pm 12$ & $58 \pm 12$ & $58 \pm 12$ & $57 \pm 11$ & $58 \pm 11$ & $58 \pm 11$ & $57 \pm 12$ \\
\hline $\mathrm{BMI} \mathrm{kg} \cdot \mathrm{m}^{-2}$ & $25 \pm 2$ & $24 \pm 2$ & $25 \pm 1$ & $29 \pm 1$ & $29 \pm 1$ & $29 \pm 1$ & $37 \pm 7$ & $38 \pm 7$ & $36 \pm 3$ \\
\hline \multirow[t]{2}{*}{ AHI events $\cdot \mathrm{h}^{-1}$} & $23 \pm 22$ & $40 \pm 20 *$ & $7 \pm 4$ & $31 \pm 25$ & $44 \pm 22 *$ & $8 \pm 4$ & $41 \pm 27$ & $50 \pm 22 *$ & $7 \pm 5$ \\
\hline & \multicolumn{6}{|c|}{$\begin{array}{l}\text { Age yrs } \\
52-53\end{array}$} & \multicolumn{3}{|c|}{$>63$} \\
\hline Population & All & OSA & Snorers & All & OSA & Snorers & All & OSA & Snorers \\
\hline Subject $n$ & 45 & 25 & 20 & 48 & 33 & 15 & 47 & 36 & 11 \\
\hline Age yrs & $42 \pm 7$ & $43 \pm 7$ & $42 \pm 6$ & $57 \pm 3$ & $57 \pm 3$ & $56 \pm 3$ & $69 \pm 6$ & $69 \pm 6$ & $69 \pm 4$ \\
\hline $\mathrm{BMI} \mathrm{kg} \cdot \mathrm{m}^{-2}$ & $31 \pm 8$ & $34 \pm 9 *$ & $29 \pm 6$ & $33 \pm 7$ & $34 \pm 7 *$ & $29 \pm 5$ & $32 \pm 8$ & $33 \pm 9$ & $32 \pm 7$ \\
\hline AHI events $\cdot h^{-1}$ & $32 \pm 31$ & $53 \pm 28 *$ & $6 \pm 4$ & $32 \pm 23$ & $42 \pm 20 *$ & $8 \pm 4$ & $38 \pm 24$ & $47 \pm 19 *$ & $8 \pm 5$ \\
\hline
\end{tabular}

Values are presented as mean \pm SD. $*: p<0.05$ OSA $v s$ snorers in the same subgroup. For definitions see legend to table 1. 

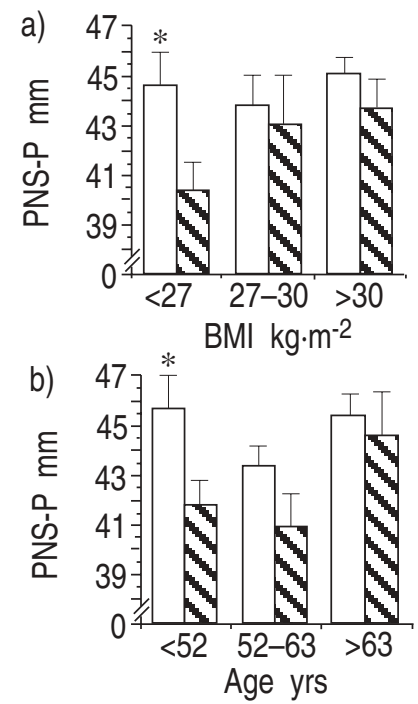
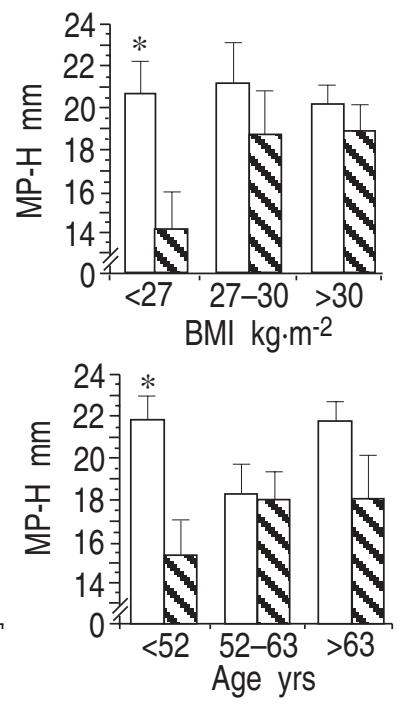

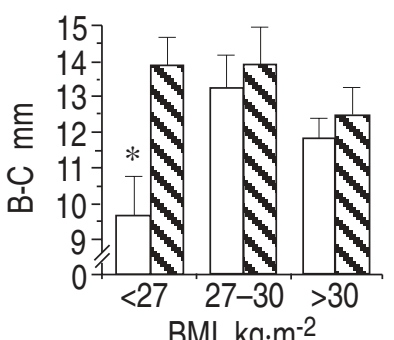

BMl $\mathrm{kg} \cdot \mathrm{m}^{-2}$

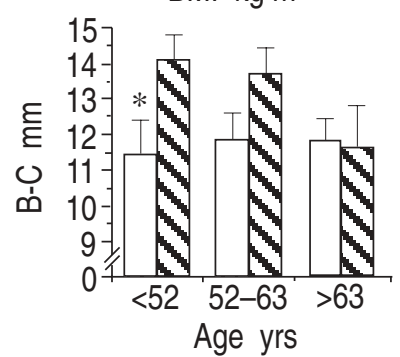

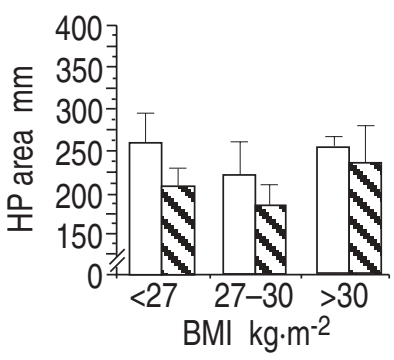

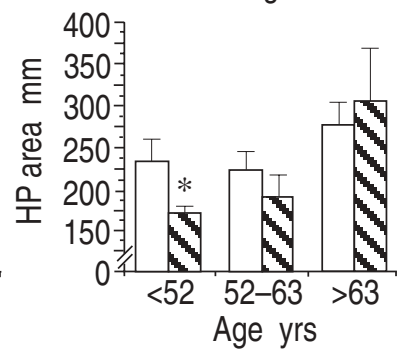

Fig. 2. - Differences between obstructive sleep apnoea (OSA) patients and snorers with respect to class of: a) body mass index (BMI); and b) age. Values are presented as mean \pm SD. Note that the significant differences seen in the overall population (table 3 ) between OSA patients and snorers for the length of the soft palate (PNS-P), position of the hyoid bone (MP-H), position of the mandible relative to the cranial base (B-C length), and hypopharyngeal (HP) area were retrieved only in lean and/or youngest subgroups. There were no differences between older or heavier OSA patients and snorers for these upper airway variables. $\square:$ OSA; snorers. *: p<0.05, OSA vs snorers in the same subgroup of age or BMI (Bonferroni test).

Relationship between BMI, age and upper airway morphology

Subgroups of BMI. The skeletal boundary enclosing the upper airway (surface "Su" and distance "L"), the tongue base (GW, IHL), the posterior airway space (fig. 3) and the soft palate width increased with BMI. There were no differences between BMI classes as regards the position of the hyoid bone, the PNS-P or the position of the mandible (MP-H, PNS-P and B-C length). Due mainly to a smaller transverse axis, the upper airway lumen of the oropharynx and hypopharynx tended to be more spherical in the higher BMI groups both in OSA patients and snorers.

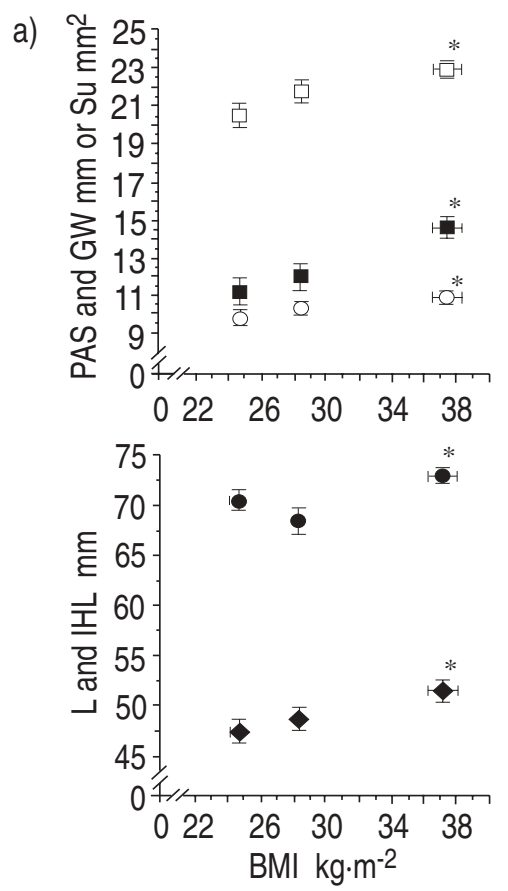

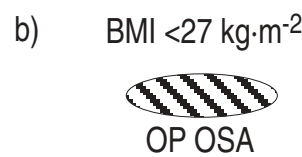

Area: $108(88) \mathrm{mm}^{2}$

AP/T ratio: $0.41(0.32)$

WIN

OP S

Area: $107(57) \mathrm{mm}^{2}$

AP/T ratio: $0.39(0.25)$

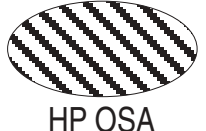

Area: $256(156) \mathrm{mm}^{2}$ AP/T ratio: $0.65(0.38)$

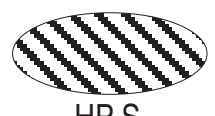

HP S

Area: $203(99) \mathrm{mm}^{2}$

AP/T ratio: $0.57(0.27)$
$\mathrm{BMI}>30 \mathrm{~kg} \cdot \mathrm{m}^{-2}$

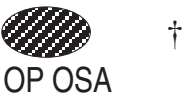

Area: $82(49) \mathrm{mm}^{2}$

AP/T ratio: $0.71(0.39)$

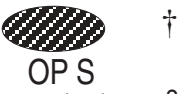

Area: $77(52) \mathrm{mm}^{2}$

AP/T ratio: 0.62 (0.30)

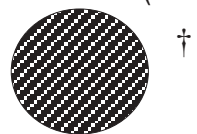

HP OSA

Area: 251 (124) $\mathrm{mm}^{2}$

AP/T ratio: 0.90 (0.36)

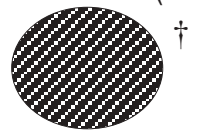

$\mathrm{HP} \mathrm{S}$

Area: 232 (192) $\mathrm{mm}^{2}$ AP/T ratio: $0.90(0.46)$

Fig. 3. - Changes in upper airway morphology in relation to body mass index (BMI). a) Absolute values presented as mean $\pm(\mathrm{SD}$;) and b) illustration of the respective change in anteroposterior (AP) and transverse (T) diameters. a) Note that the the skeletal boundary enclosing the upper airway as evaluated by surface (Su) and distance (L), the base of tongue (genioglossal width (GW), interhyoglossal length (IHL)) and posterior

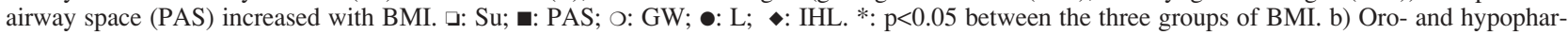
ynx became more spherical at higher BMI both in obstructive sleep apnoea (OSA) and snorers (S), without significant change in area. The shape of the oropharynx (OP) and hypopharynx (HP) were drawn from the mean values of the AP and T axis. This approximates the global surface and may explain the discrepancy between some surfaces illustrated above and the actual measured area. $\mathrm{kg} \cdot \mathrm{m}^{-2}$. $\dagger$ : transverse length was significantly shorter ss $\mathrm{BMI}<27 \mathrm{~kg} \cdot \mathrm{m}^{-2}$. 
Subgroups of age. Older patients had larger upper airways than the youngest group of patients at all pharyngeal levels (fig. 4). No significant changes in pharyngeal shape or in the cephalometric variables were seen in relation to age.

Relationship between upper airway measurements and AHI (table 4 and fig. 5)

Correlation studies. In the overall population, BMI was significantly correlated with AHI but age was not. PNS-P, position of the hyoid bone (MP-H), position of the mandible (B-C length), size of the base of tongue (GW, IHL) and configuration of the pharyngeal lumen (increased $\mathrm{AP} / \mathrm{T}$ ratio of the $\mathrm{OP}$ and $\mathrm{HP}$ ) were all significantly correlated with AHI.

In the subgroup of patients with a BMI $<27 \mathrm{~kg} \cdot \mathrm{m}^{-2}$, age, BMI, PNS-P, position of the hyoid bone (MP-H), position of mandible (B-C length) and HP were significantly correlated with AHI. In the group with a BMI $>30$ $\mathrm{kg} \cdot \mathrm{m}^{-2}$, only the position of the hyoid bone (MP-H) was significantly correlated with AHI.

In the subgroup of patients aged $<52$ yrs, BMI, soft palate length (PNS-P), position of the hyoid bone (MP$\mathrm{H}$ ), genioglossal width, and configuration of the oropharyngeal lumen (increased $\mathrm{AP} / \mathrm{T}$ ratio of the $\mathrm{OP}$ ) were significantly correlated with AHI, while only age was significantly correlated with AHI in the group $>63$ yrs.

Figure 5 illustrates the loss of significance of correlation coefficients from lean to obese subjects. Thus for $\mathrm{B}-\mathrm{C}$ length and MP-H the $\mathrm{r}$ values were respectvely 0.55 , $0.01,0.09$ and $0.54,0.23,0.18$ when the BMI increased from $<27 \mathrm{~kg} \cdot \mathrm{m}^{-2}$ to $>30 \mathrm{~kg} \cdot \mathrm{m}^{-2}$.

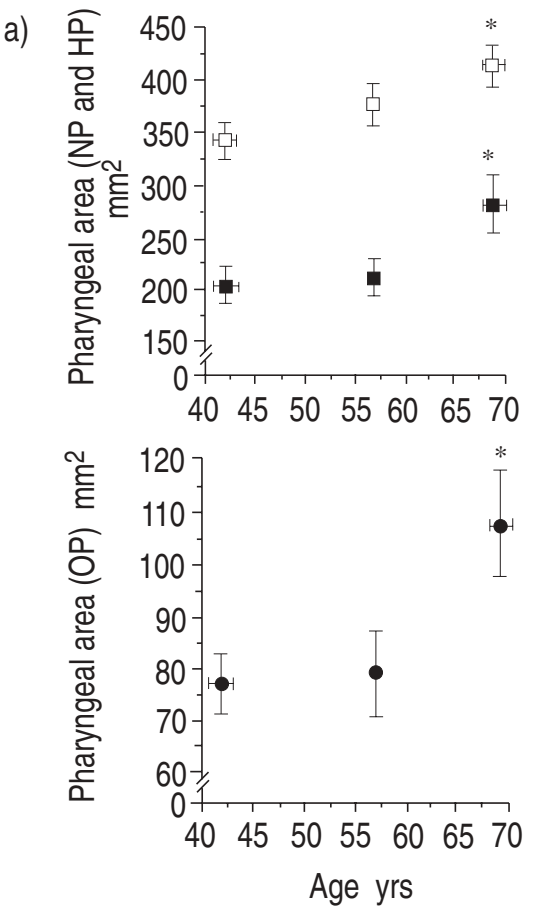

b)
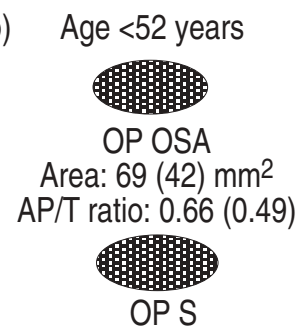

Area: $86(27) \mathrm{mm}^{2}$
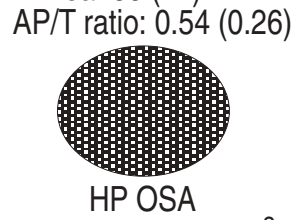

Area: $232(141) \mathrm{mm}^{2}$

AP/T ratio: $0.54(0.55)$

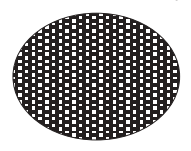

HP S

Area: $170(141) \mathrm{mm}^{2}$ AP/T ratio: $0.79(0.41)$
Table 4. - Correlation of upper airway variables with AHI in the whole group (overall) and as a function of their $\mathrm{BMI}$ and Age

\begin{tabular}{|c|c|c|c|c|c|}
\hline \multirow[b]{2}{*}{ Variables } & \multirow{2}{*}{$\begin{array}{l}\text { Overall } \\
\text { population } \\
(\mathrm{n}=140)\end{array}$} & \multirow{2}{*}{\multicolumn{2}{|c|}{\begin{tabular}{cc}
\multicolumn{2}{c}{ Subgroups of } \\
BMI & $\mathrm{kg} \cdot \mathrm{m}^{-2}$ \\
$<27$ & $>30$ \\
$(\mathrm{n}=36)$ & $(\mathrm{n}-72)$
\end{tabular}}} & \multicolumn{2}{|c|}{$\begin{array}{c}\text { Subgroups of } \\
\text { age yrs }\end{array}$} \\
\hline & & & & $\begin{array}{c}<52 \\
(\mathrm{n}=45)\end{array}$ & $\begin{array}{c}>63 \\
(\mathrm{n}=47)\end{array}$ \\
\hline Age yrs & $0.16^{\S}$ & $0.46^{* *}$ & -0.12 & 0.12 & $0.30^{*}$ \\
\hline $\mathrm{BMI} \mathrm{kg} \cdot \mathrm{m}^{-2}$ & $0.28 * * *$ & $-0.35^{*}$ & 0.17 & $0.54 * * *$ & $*^{*}-0.07$ \\
\hline \multicolumn{6}{|l|}{ Cephalometry } \\
\hline PNS-P & $0.24 * *$ & $0.39 *$ & 0.07 & $0.34 *$ & -0.01 \\
\hline MP-H & $0.35^{* * *}$ & $0.35^{*}$ & $0.32 * *$ & $0.54 * * *$ & * 0.18 \\
\hline PAS & 0.11 & 0.08 & -0.01 & 0.29 & -0.13 \\
\hline SPW & 0.17 & -0.05 & 0.09 & 0.19 & 0.06 \\
\hline A-B length & -0.09 & -0.05 & -0.14 & -0.25 & 0.02 \\
\hline B-C length & $-0.25^{*}$ & $-0.55 * * *$ & -0.10 & -0.24 & 0.05 \\
\hline A-C length & 0.05 & 0.28 & -0.09 & -0.08 & -0.01 \\
\hline \multicolumn{6}{|c|}{ Computed tomography } \\
\hline $\mathrm{NP}$ & -0.08 & 0.29 & -0.10 & -0.15 & -0.06 \\
\hline OP area & -0.10 & 0.15 & -0.06 & -0.26 & -0.01 \\
\hline HP area & 0.12 & $0.38 *$ & 0.06 & 0.14 & 0.02 \\
\hline $\mathrm{Su}$ & 0.09 & 0.21 & 0.01 & 0.13 & 0.05 \\
\hline $\mathrm{L}$ & 0.001 & 0.14 & -0.10 & -0.14 & 0.13 \\
\hline $\mathrm{AP} / \mathrm{T}$ ratio $\mathrm{NP}$ & -0.10 & -0.13 & -0.12 & -0.16 & -0.13 \\
\hline $\mathrm{AP} / \mathrm{T}$ ratio $\mathrm{OP}$ & $0.29 *$ & 0.08 & 0.18 & $0.30^{*}$ & -0.004 \\
\hline $\mathrm{AP} / \mathrm{T}$ ratio $\mathrm{HP}$ & $0.19 *$ & 0.13 & 0.10 & 0.21 & 0.06 \\
\hline IHL & $0.22^{*}$ & -0.26 & 0.17 & 0.16 & 0.11 \\
\hline GW & $0.25 * *$ & -0.01 & 0.10 & $0.36^{*}$ & -0.06 \\
\hline
\end{tabular}

$\S$ : all numbers are $\mathrm{r}$ values. $*$ : $\mathrm{p}<0.05 ; * *$ : $\mathrm{p}<0.01 ; * * *: \mathrm{p}<0.001$. Note that many anthropometric and upper airway variables were However, those sianificant AHI in the overall population. of the good correlations in lean or younger subjects, upper airway variables being poorly correlated with $\mathrm{AHI}$ in heavier or older groups. For abbreviations see legends to table 1 and 3 .

Fig. 4. - Changes in upper airway morphology in relation to age. a) Absolute values presented as mean $( \pm \mathrm{SD})$; and b) illustration of the respective change in anteroposterior and transverse diameters. a) Note that the area of the naso- (NP), oro- (OP), and hypopharynx (HP) increased in relation to age. $\square$ : NP; $\mathbf{\square}$ : HP; $\bullet$ : OP. *: p<0.05 between the three groups of age by analysis of variance. b) No change in shape was observed. 明明 : $<52$ yrs; : $:>63$ yrs. 

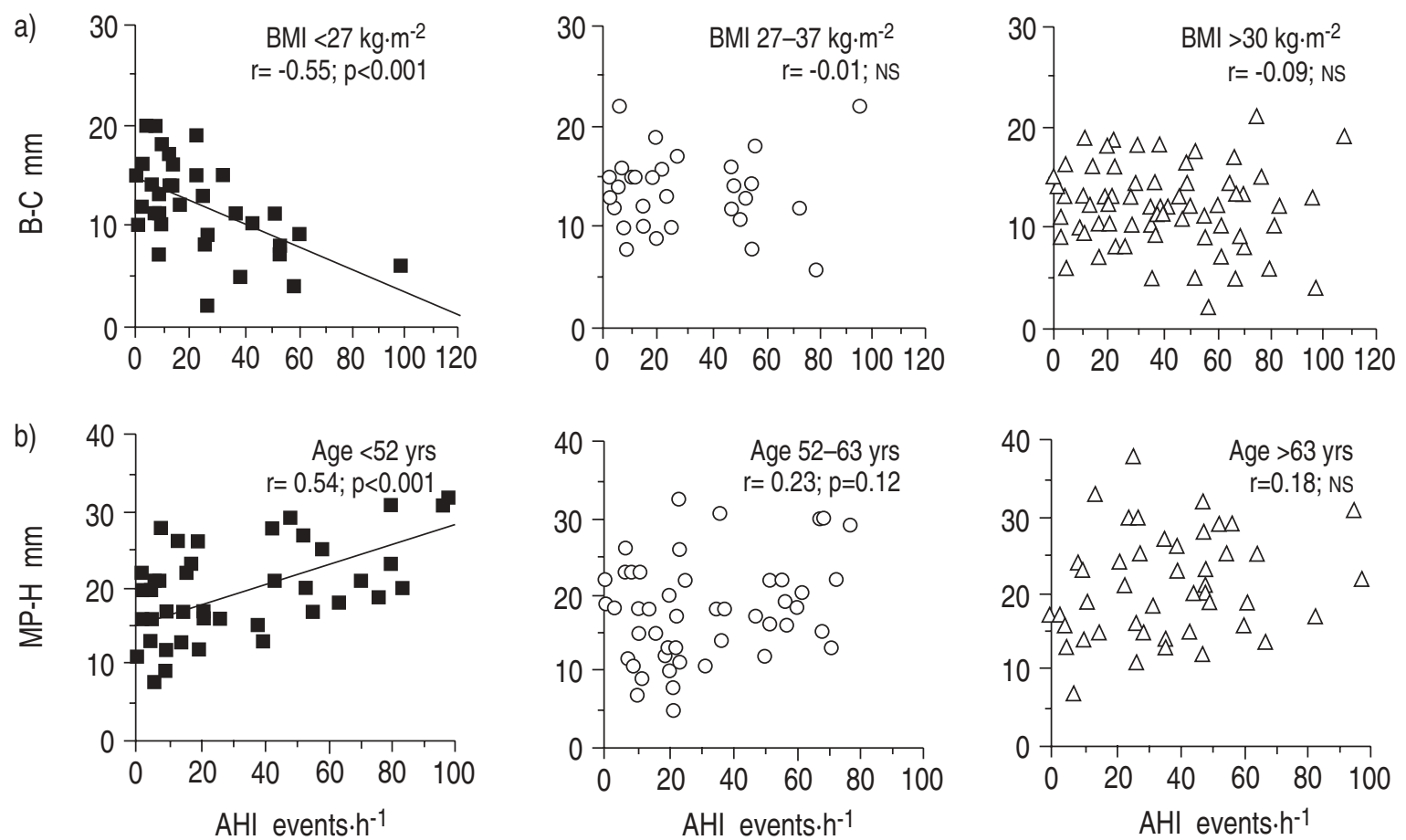

Fig. 5. - This example illustrates the loss of significance of correlation coefficients of: a) the position of the mandible (B-C length); and b) the position of the hyoid bone (MP-H), with apnoea/hypopnoea index (AHI) as class of a) body mass index (BMI) and b) age increase, respectively. ns: nonsignificant.

Multiple stepwise linear regressions. Stepwise regressions using all the upper airway variables previously described were performed for the overall population and the different classes of BMI and age (table 5).

For the overall population, where all the variables were available $(n=110)$, the model explained $26 \%$ of the variance in AHI $\left(\mathrm{AHI}=1.45^{*} \mathrm{MP}-\mathrm{H}+4.07 * \mathrm{GW}-0.67^{*} \mathrm{AB}\right.$ $+19.23)$.

In the group with a BMI $<27 \mathrm{~kg} \cdot \mathrm{m}^{-2}(\mathrm{n}=28)$, the model explained $69 \%$ of the variance of the $\mathrm{AHI}(\mathrm{AHI}=$ $-2.65 * \mathrm{~B}-\mathrm{C}+2.14 * \mathrm{PNS}-\mathrm{P}+0.78^{*}$ Age $-5.62 * \mathrm{GW}-23.35$ ), which contrasts with the group with a BMI $>30 \mathrm{~kg} \cdot \mathrm{m}^{-2}$

Table 5. - Multiple stepwise regression with AHI as dependent variable

\begin{tabular}{lcccc}
\hline & Variable & $\begin{array}{c}\text { Order of } \\
\text { selection }\end{array}$ & $\begin{array}{c}\text { Partial } \\
\mathrm{r}^{2}\end{array}$ & $\begin{array}{c}\text { Model } \\
\mathrm{r}^{2}\end{array}$ \\
\hline Overall & MP-H & 1 & 0.14 & 0.14 \\
& GW & 2 & 0.08 & 0.22 \\
& A-B & 3 & 0.03 & 0.25 \\
BMI $<27 \mathrm{~kg} \cdot \mathrm{m}^{-2}$ & BC & 1 & 0.29 & 0.29 \\
& PNS-P & 2 & 0.17 & 0.46 \\
& Age & 3 & 0.11 & 0.58 \\
& GW & 4 & 0.11 & 0.69 \\
BMI $>30 \mathrm{~kg} \cdot \mathrm{m}^{-2}$ & MP-H & 1 & 0.15 & 0.15 \\
Age $<52 \mathrm{yrs}$ & MP-H & 1 & 0.32 & 0.32 \\
& GW & 2 & 0.13 & 0.45 \\
Age $>63$ yrs & A-B & 3 & 0.10 & 0.55 \\
\hline
\end{tabular}

Note that in the overall population the model explained only $26 \%$ of the variance in AHI. In lean $\left(\mathrm{BMI}<27 \mathrm{~kg} \cdot \mathrm{m}^{-2}\right)$ or youngest (age $<52 \mathrm{yrs}$ ) groups the percentage increased to 69 and $55 \%$, respectively. In the group with a $\left(\mathrm{BMI}>30 \mathrm{~kg} \cdot \mathrm{m}^{-2}\right.$ ) only $15 \%$ of the variance in AHI was explained, and none in older (age $>63 \mathrm{yrs}$ ) patients. For definitions see legends to table 1 and 3 . $(n=56)$, where the only upper airway variable retained (MP-H) explained 15\% of the variance of the AHI (AHI $=1.69 * \mathrm{MP}-\mathrm{H}+5.03)$.

In the subgroup of patients aged $<52 \mathrm{yrs}(\mathrm{n}=36)$, the model explained $55 \%$ of the variance of $\mathrm{AHI}(\mathrm{AHI}=$ $2.07 * \mathrm{MP}-\mathrm{H}+6.49 * \mathrm{GW}-1.41 * \mathrm{AB}+48.31)$, while no variable was retained in the class $>63 \mathrm{yrs}$.

\section{Discussion}

We report a large study using a combination of the two most widely available static upper airway imaging techniques (cephalometry and CT) in the evaluation of snorers with and without OSA. The main finding of this study is that in younger and lean subjects a major part of the variance in AHI is explained by upper airway measurements. Another important new finding is the change in upper airway shape with BMI which, in contrast to previous reports [21-24], was independent of the presence or absence of OSA.

In agreement with previous studies [1,2], it was found that OSA patients had more upper airway abnormalities than snorers. Thus, greater PNS-P, increased base of the tongue (IHL, GW), inferior position of the hyoid bone and posterior displacement of the mandible, were found in OSA patients compared to snorers. When subdivided for BMI or age, however, it was found that the significant differences between the upper airway measurements of OSA patients and snorers in the overall population were derived almost exclusively from the subgroups with a BMI $<27 \mathrm{~kg} \cdot \mathrm{m}^{-2}$ or an age $<52 \mathrm{yrs}$. Obese or older OSA patients were not different from obese or older snorers as regards their upper airway anatomy.

Why do the differences between OSA patients and snorers not persist in higher BMI groups or later in life? 
Among the possible explanations could be the presence of confounding factors related either to group subdivisions or to the criteria used for selecting nonapnoeic or mild apnoeic snorers. Lean snorers were, on average, 9 yrs younger than lean OSA patients and, conversely, younger snorers were slimmer $\left(\Delta \mathrm{BMI}=5 \mathrm{~kg} \cdot \mathrm{m}^{-2}\right)$ than younger OSA patients. Significant differences were found between lean or younger OSA patients and snorers in MP-H, PNS$\mathrm{P}$ and $\mathrm{B}-\mathrm{C}$ length, but a separate ANOVA for age in lean subjects and for BMI in youngest ones found no difference between groups for these parameters. Therefore, age and BMI are unlikely to be real confounding factors explaining the differences between OSA patients and snorers in lean or younger subjects. As regards the definition of snorers, using an AHI $<10$ as cut-off point did not change the results. Finally, it is more likely that upper airway abnormalities in obese or older patients could be a consequence of increasing BMI or age.

The principal changes in upper airway morphology observed in the different subgroups of BMI concerned the shape of the oropharyngeal and hypopharyngeal lumens. Both in OSA patients and snorers, the lumen became more spherical in the highest BMI group. This was mainly secondary to a decrease in the transverse axes of the OP and HP, without significant changes in surface area. This questions the conclusions of RODENSTEIN et al. [21] and ScHWAB et al. [24], who showed that OSA patients and, to a lesser extent, snorers had a pharynx with a predominant anteroposterior axis or a circular pharynx, as opposed to normals who had a predominant transverse axis. In those studies [21, 24], apnoeics were much more overweight than snorers or normals. Thus, their results could be related more to the difference in BMI between groups than a characteristic of OSA. The mechanisms involved in this change of pharyngeal shape with BMI could be fat infiltration in the lateral portion of the airway as described in OSA patients [32, 33], or a result of the increased upper airway dilator muscle activity described in awake OSA patients [34].

Regarding the relationship between BMI and upper airway morphology, TsuchiYA et al. [35] reported in a group of OSA patients that those with a high apnoea index but a low BMI had skeletal abnormalities (retruded mandible, higher mandibular plane angle), whilst patients with a low apnoea index but high BMI had soft tissue changes (increased soft palate area, lower hyoid bone). In a recent study, only in OSA patients, FERGUSON et al. [26] investigated the relationship between neck size and upper airway abnormalities. They showed that patients with larger neck size (obese) had increased upper airway soft tissue structure (soft palate and tongue) and lower hyoid bone, whilst patients with smaller neck size (non-obese) demonstrated abnormal craniofacial structure (biretromaxilly). We found, similarly, an increased base of the tongue and soft palate width in more obese patients and a smaller skeletal boundary enclosing the upper airway in nonobese patients. However, these modifications appeared both in OSA patients and snorers and again seem a consequence of the change in BMI rather than a characteristic of a subtype of OSA. This finding questions the particular role of these upper airway changes in OSA pathophysiology and emphasize the need to use controls matched for BMI. Older patients $(>63 \mathrm{yrs})$ had larger upper airway than younger patients $(<52 \mathrm{yrs})$ at all pharyngeal levels. This confirms the results previously found in OSA patients [25] and in normals [22], but does not support the protective effect of a larger upper airway in normal elderly subjects [22], a larger upper airway being observed both in OSA patients and snorers.

Previous studies [1, 4] looking at upper airway measurements and anthropometric results as determinants of AHI showed that upper airway variables explained a low percentage of the variance in AHI. Overall, we were able to explain $26 \%$ of the variance in AHI using upper airway measurements and anthropometric data. This is comparable with the $32 \%$ found by PARTINEN et al. [4] using upper airway variables alone. Our findings are also in accordance with the results of ZuCCONI et al. [1], who reported that using upper airway abnormalities they could explain $33 \%$ of the variance in AHI. Conversely, in our study, upper airway abnormalities found in lean or younger patients were better correlated with $\mathrm{AHI}$ and explained more of the variance in AHI (69 and 55\%, respectively) than in obese or older patients and, thus, seem more likely to play an important physiopathogenic role for OSA in these patients.

The fact that upper airway abnormalities do not correlate significantly with $\mathrm{AHI}$ in older or more obese subjects suggests that other pathophysiological mechanisms, such as increased upper airway collapsibility, fragmented sleep, ventilatory instability and neurological mechanisms (changes in upper airway dilator muscle activity) may be more important in such patients who develop OSA. In lean or younger subjects, two skeletal abnormalities appeared in multiple stepwise regression to be significant determinants of AHI. These are the position of the mandible (B-C length), which was the major determinant in leaner subjects, and the length of the mandible (A-B length) in the youngest group. These skeletal abnormalities possibly imply a genetic predisposition to OSA in such patients. This is in agreement with a recent study [36] of familial factors in OSA, showing that relatives of OSA patients with a BMI $<30 \mathrm{~kg} \cdot \mathrm{m}^{-2}$ had narrower upper airway with retroposed maxillae and mandibles compared to controls. However, we cannot exclude childhood developmental abnormalities related to predominant mouth breathing [37], or other mechanisms.

In conclusion, the differences observed between obstructive sleep apnoea patients and snorers in the overall population were due only to the subgroups of lean or younger subjects. Consequently, upper airway abnormalities found in lean or younger subjects explain a higher percentage of apnoea/hypopnoea index variance and, thus, are more likely to play a more important physiopathogenic role for obstructive sleep apnoea than in obese or older patients. Our study also suggests that the shape of the pharyngeal lumen in awake subjects is more dependent on body mass index than on the presence of obstructive sleep apnoea. Future studies looking at upper airway imaging for surgical selection should be focused on young and lean patients.

\section{References}

1. Zucconi M, Ferini-Strambi L, Palazzi S, Orena C, Zonta S, Smirne S. Habitual snoring with and without obstructive sleep apnea: the importance of cephalometric variables. Thorax 1992; 47: 157-161. 
2. Maltais F, Carrier G, Cormier Y, Sériès F. Cephalometric measurements in snorers, nonsnorers, and patients with sleep apnea. Thorax 1991; 46: 419-423.

3. Polo OJ, Tafti M, Fraga J, Porkka K, Dejean Y, Billiard M. Why don't all heavy snorers have obstructive sleep apnea? Am Rev Respir Dis 1991; 143: 1288-1293.

4. Partinen M, Guilleminault C, Quera-Salva MA, Jamieson A. Obstructive sleep apnea and cephalometric roentgenograms: the role of anatomic upper airway abnormalities in the definition of abnormal breathing during sleep. Chest 1988; 93: 1199-1205.

5. Riley R, Guilleminault C, Herran J, Powel N. Cephalometric analyses and flow-volume loops in obstructive sleep apnea patients. Sleep 1983; 6: 303-311.

6. Bohlman ME, Haponik EF, Smith PL, Allen RP, Bleecker ER, Goldman SM. CT demonstration of pharyngeal narrowing in adult obstructive sleep apnea. AJR 1983; 140: 543-548.

7. Haponik EF, Smith PL, Bohlman ME, Allen RP, Goldman SM, Bleecker ER. Computerized tomography in obstructive sleep apnea: correlation of airway size with physiology during sleep and wakefulness. Am Rev Respir Dis 1983; 127: 221-226.

8. Guilleminault C, Riley R, Powell N. Obstructive sleep apnea and abnormal cephalometric measurements. Implication for treatment. Chest 1984; 86: 793-794.

9. Rivlin J, Hoffstein V, Kalbfleisch J, McNicholas W, Zamel N, Bryan AC. Upper airway morphology in patients with idiopathic obstructive sleep apnoea. Am Rev Respir Dis 1984; 129: 355-360.

10. Jamieson A, Guilleminault C, Partinen M, Quera-Salva MA. Obstructive sleep apneic patients have craniomandibular abnormalities. Sleep 1986; 9: 469-477.

11. Lowe AA, Gionhaku N, Takeuchi K, Fleetham JA. Three-dimensional CT reconstructions of tongue and airway in adult subjects with obstructive sleep apnea. $A m$ J Orthod Dentofac Orthop 1986; 90: 364-374.

12. Brown IG, Zamel N, Hoffstein V. Pharyngeal cross-sectional area in normal men and women. J Appl Physiol 1986; 61: 890-895.

13. Stauffer JL, Zwillich CW, Cadieux RJ, et al. Pharyngeal size and resistance in obstructive sleep apnea. Am Rev Respir Dis 1987; 136: 623-627.

14. De Berry-Borowiecki B, Kukwa A, Blanks RHI. Cephalometric analysis for diagnosis and treatment of obstructive sleep apnea. Laryngoscope 1988; 98: 226-234.

15. Larsson SG, Gislason T, Lindholm CE. Computed tomography of the oropharynx in obstructive sleep apnea. Acta Radiol 1988; 29: 401-405.

16. Strelzow VV, Blanks RHI, Basile A, Strelzow AE. Cephalometric airway analysis in obstructive sleep apnea syndrome. Laryngoscope 1988; 98: 1149-1158.

17. Lyberg T, Krogstad O, Djupesland G. Cephalometric analysis in patients with obstructive sleep apnea syndrome. I. Skeletal morphology. J Laryngol Otol 1989; 103: 287-292.

18. Lyberg T, Krogstad O, Djupesland G. Cephalometric analysis in patients with obstructive sleep apnea syndrome. II. Soft tissue morphology. J Laryngol Otol 1989; 103: 293-297.

19. Horner RL, Shea SA, McIvor J, Guz A. Pharyngeal size and shape during wakefulness and sleep in patients with obstructive sleep apnoea. Q J Med 1989; 268: 719- 735.

20. Stauffer JL, White DP, Zwillich CW. Pulmonary function in obstructive sleep apnea: relationships to pharyngeal resistance and cross-sectional area. Chest 1990; 97 : 302-307.

21. Rodenstein DO, Dooms G, Thomas Y, et al. Pharyngeal shape and dimensions in healthy subjects, snorers, and patients with obstructive sleep apnea. Thorax 1990; 45: 722-727.

22. Burger CD, Stanson AW, Sheedy PF II, Daniels BK, Shepard JW. Fast-computed tomography evaluation of agerelated changes in upper airway structure and function in normal men. Am Rev Respir Dis 1992; 145: 846-852.

23. Shelton KE, Gay SB, Hollowell DE, Woodson H, Suratt PM. Mandible enclosure of upper airway and weight in obstructive sleep apnea. Am Rev Respir Dis 1993; 148: 195-200.

24. Schwab RJ, Gefter WB, Hoffmann EA, Gupta KB, Pack AI. Dynamic upper airway imaging during awake respiration in normal subjects and patients with sleep disordered breathing. Am Rev Respir Dis 1993; 148: 1385-1400.

25. Lévy P, Pépin JL, Malauzat D, Emeriau JP, Léger JM. Is sleep apnea syndrome in the elderly a specific entity? Sleep 1996; 19: S29-S38.

26. Ferguson KA, Ono T, Lowe AA, Ryan F, Fleetham JA. The relationship between obesity and craniofacial structure in obstructive sleep apnea. Chest 1995; 108: 375-381.

27. Bacon WH, Krieger J, Turlot JC, Stierle JL. Craniofacial characteristics in patients with obstructive sleep apneas syndrome. Cleft Palate J 1988; 25: 374-378.

28. Medical section of the American Lung Association. Indications and standards for cardiopulmonary sleep studies. Am Rev Respir Dis 1989; 139: 559-568.

29. Rechtschaffen A, Kales A. US Department of Health, Education and Welfare. A manual of standardized terminology, techniques and scoring system for sleep stages of human subjects. Publication No. (NIH)204, 1968, National Institute of Health.

30. Gould GA, Whyte KF, Rhind GB, et al. The sleep hypopnoea syndrome. Am Rev Respir Dis 1988; 137: 895-898.

31. Dixon WJ, Brown MB, Engelman L, Jennrich RI. BMDP statistical software. Los Angeles, University of California Press, 1990; Vol. 1, 2.

32. Horner RL, Mohiaddin RH, Lowell DG, et al. Sites and sizes of fat deposits around the pharynx in obese patients with obstructive sleep apnea and weight matched controls. Eur Respir J 1989; 2: 613-622.

33. Shelton KE, Woodson H, Gay S, Suratt PM. Pharyngeal fat in obstructive sleep apnea. Am Rev Respir Dis 1993; 148: 462-466.

34. Mezzanotte WS, Tangel DJ, White DP. Waking genioglossal electromyogram in sleep apnea patients versus normal controls (a neuromuscular compensatory mechanism). J Clin Invest 1992; 89: 1571-1579.

35. Tsuchiya M, Lowe AA, Pae EK, Fleetham JA. Obstructive sleep apnea subtypes by cluster analysis. Am J Orthod Dentofac Orthop 1992; 101: 533-542.

36. Mathur R, Douglas NJ. Family studies in patients with the sleep apnea-hypopnea syndrome. Ann Intern Med 1995; 122: 174-178.

37. Tomer BS, Harvold EP. Primate experiments on mandibular growth direction. Am J Orthod 1982; 82: 115-119. 